\title{
EVOLUTION OF THE SPECTROSCOPIC PROPERTIES OF Hg AND Hg2 INTERACTING WITH MOLECULAR CLUSTERS
}

\author{
C. DEDONDER-LARDEUX, S. MARTRENCHARD-BARRA, C. JOUVET, \\ D. SOLGADI,
}

Laboratoire de Photophysique moléculaire du CNRS

Bat 213, Université de Paris Sud

91405 Orsay cedex, France

\author{
F. AMAR \\ Department of Chemistry \\ University of Maine \\ Orono, Maine 04469, USA
}

\begin{abstract}
The spectroscopic properties of mercury and mercury dimer clustered with water, ammonia and 1-1 dimethylether have been studied through mass selected resonance enhanced multiphoton ionization spectroscopy. The ground state structure of these clusters have been calculated. Comparison between calculations and experimental results show that the spectrum is not governed by the structural properties of the clusters.
\end{abstract}

KEY WORDS: Electronic spectra of $\mathrm{Hg}_{1,2}(\mathrm{Mol})_{\mathrm{n}}$, molecular dynamics simulations, molecular solvation of mercury, qusi-chemical bond

\section{INTRODUCTION}

The interactions between metal atoms and molecules are determinant to understand physical or chemical behavior of these metal atoms suspended in solution. The large applications of organo metallic complexes in synthesis, catalysis, biology etc . . . is well known and widely studied. The study of these complexes produced in supersonic experiments may help to make the link between the gas and the condensed phase, since clusters may be considered as microscopic models.

This approach has already been used to understand the solvation processes of molecules (mainly aromatic ones) and has led to the characterization of many 1-1 complexes and in this field the works of Prof. M. Ito can be considered as benchmarks. ${ }^{1,2}$ 
In our experiments, we can produce size controlled clusters and study their properties selectively as a function of the number of "solvent molecules" and/or metallic atoms associated with these molecules.

An increasing number of publications based on the same approach is appearing in the literature. Most of them are dealing with properties of these complexes after ionization (ionization threshold measurements, determination of binding energies of $\mathrm{M}^{+}(\mathrm{Mol})_{\mathrm{n}}^{3-9} \ldots$...) and concern different metallic atoms (alkaline, nickel, for example).

The questions addressed in this paper can be summarized as follows:

- How are the spectroscopic properties of an atom or a dimer influenced by step by step solvation?

- Can the spectroscopy give information on the solvation process i.e. can we observe a strong change in the spectroscopy for systems where an atom is inside the cluster as compared to a system where the atom sits on the molecular cluster. This refers to the question of wetting non-wetting transitions widely studied for aromatic rare gas clusters. ${ }^{10,11}$

Apart from the studies on metal-rare gas experiments concerning the spectroscopy of excited metal-molecule complexes concern mostly the mercury atom. As the spectroscopy of the 1-1 complex is known for $\mathrm{NH}_{3}$ and $\mathrm{H}_{2} \mathrm{O},{ }^{14,15,16}$ mercury seems to be a good choice to study the effect on increasing number of molecules on a metal atom.

Spectroscopic studies of the $\mathrm{Hg}$-molecule $\left(\mathrm{H}_{2} \mathrm{O}, \mathrm{NH}_{3}, \mathrm{CH}_{4}, \mathrm{H}_{2} \ldots\right)$ complexes have shown some common behavior:

- In the ground state the electronic structure of mercury is $6 \mathrm{~s}^{2}$ (closed shell), and the $\mathrm{Hg}$-molecule interaction is a weak van der Waals interaction (Binding energy from $260 \mathrm{~cm}^{-1}$ for $\mathrm{NH}_{3}$ to $300 \mathrm{~cm}^{-1}$ for $\mathrm{H}_{2} \mathrm{O}$ ).

- The excitation of the $\mathrm{Hg}\left({ }^{3} \mathrm{P}\right)$ state leads to an open shell $6 \mathrm{~s} 6 \mathrm{p}$ configuration and a strong "quasi chemical bound" is created between excited $\mathrm{Hg}$ and the molecule $\left(\mathrm{H}_{2} \mathrm{O}, \mathrm{NH}_{3}, \mathrm{H}_{2}\right)$. In the spectral region of the $\mathrm{Hg}\left({ }^{3} \mathrm{P}_{1} \leftarrow{ }^{1} \mathrm{~S}_{0}\right)$ two bound states, (A $(\Omega=0$ in $\mathrm{C} \infty \mathrm{v})$ state red shifted as compared to the $\mathrm{Hg}$ line and $\mathrm{B}(\Omega=1)$ state which is blue shifted) correlating with $\mathrm{Hg}\left({ }^{3} \mathrm{P}_{1}\right)$ have been evidenced.

The spectroscopy of $\mathrm{Hg}_{2}$ is also well characterized. ${ }^{17,18,19}$ The ground state is a van der Waals like state linked by $340 \mathrm{~cm}^{-1}$. The two photon REMPI excitation spectrum of $\mathrm{Hg}_{2}$ in the vicinity of the $\mathrm{Hg}\left({ }^{3} \mathrm{P}_{1}\right)$ transition is shown in Figure 1A: two states correlating with $\mathrm{Hg}\left({ }^{3} \mathrm{P}_{1}\right)$ have been observed.

-a first one $\left(\mathrm{Hg}_{2} 1_{u}\right)$ red shifted with respect to the atomic line is strongly bound $\left(8,260 \mathrm{~cm}^{-1}\right)$ and shows a long vibrational progression in the $260-270 \mathrm{~nm}$ range. ${ }^{17}$ - the second one $\left(\mathrm{O}_{\mathrm{u}}^{+}\right)$weakly bond by $400 \mathrm{~cm}^{-1}$ shows one band centered around $254 \mathrm{~nm}^{18}$

In a previous work, we have studied the ionization of $\mathrm{Hg}_{\mathrm{m}}={ }_{1,2}\left(\mathrm{NH}_{3}\right)_{\mathrm{n}}{ }^{12}$ and $\mathrm{Hg}_{\mathrm{m}=1,2}(\mathrm{DME})_{\mathrm{n}}{ }^{13}$ clusters (DME being Dimethylether). We have shown that the ionization threshold of the mercury atom is strongly affected by complexation and 


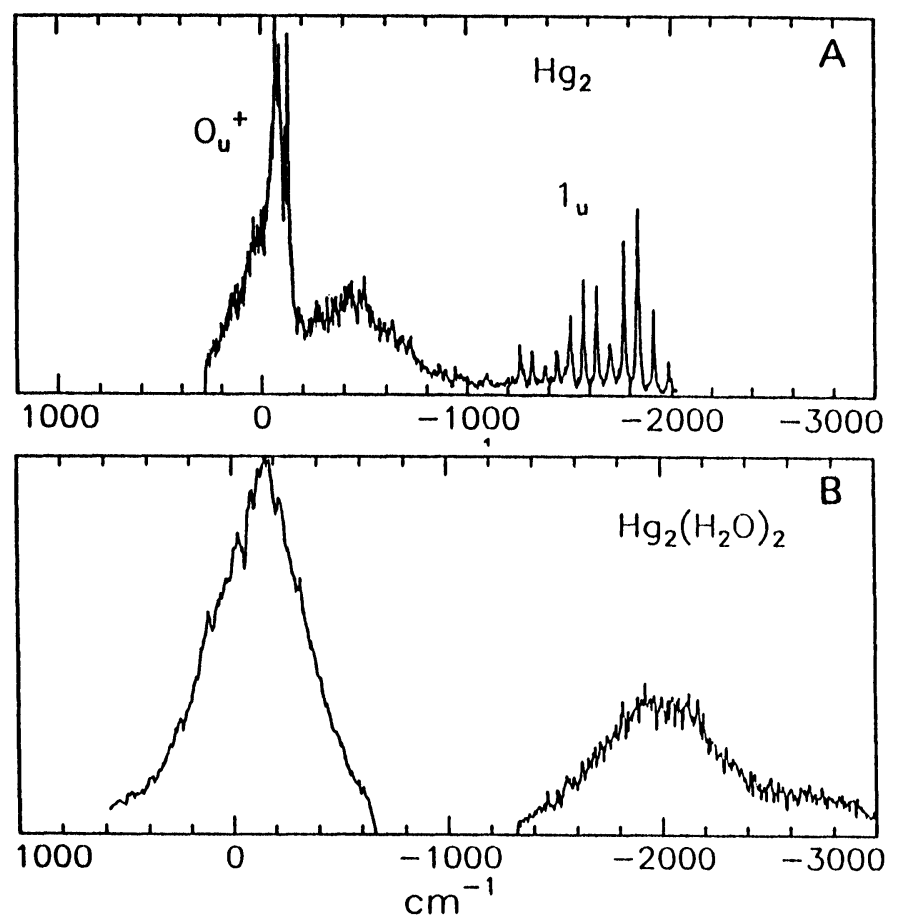

Figure 1 A) One color two photon $\mathrm{Hg}_{2}$ REMPI spectrum in the $\mathrm{Hg}\left({ }^{3} \mathrm{P}_{1} \leftarrow{ }^{1} \mathrm{~S}_{0}\right)$ spectral region. The two transitions $\left(\mathrm{O}_{\mathrm{u}}^{+} \leftarrow \mathrm{O}_{\mathrm{g}}^{+}\right)$and $\left(1 \mathrm{u} \leftarrow \mathrm{O}_{\mathrm{g}}^{+}\right)$are characterized. Although not represented in this spectrum the $\left(1 \mathrm{u} \leftarrow \mathrm{O}_{\mathrm{g}}^{+}\right)$transition can be observed up to $-2,500 \mathrm{~cm}^{-1}(17)$.

B) One color two photons $\mathrm{Hg}_{2}\left(\mathrm{H}_{2} \mathrm{O}\right)_{2}$ REMPI spectrum in the $\mathrm{Hg}\left({ }^{3} \mathrm{P}_{1} \leftarrow{ }^{1} \mathrm{~S}_{0}\right)$ spectral region. The two transitions $\left(\mathrm{O}_{\mathrm{u}}^{+} \leftarrow \mathrm{O}_{\mathrm{g}}^{+}\right)$and $\left(1 \mathrm{u} \leftarrow \mathrm{O}_{\mathrm{g}}^{+}\right)$are characterized. The intensity of this two transitions are adjusted by comparison with the spectrum $4 \mathrm{~A}$. For all the other $\mathrm{Hg}_{2}(\mathrm{Mol})_{\mathrm{n}}$ clusters studied the spectral shape are similar.

is decreasing with the number of ligands. For $\mathrm{Hg}_{2}(\mathrm{Mol})_{\mathrm{n}}$ the ionization properties change drastically from $\mathrm{Hg}_{2}\left(\mathrm{NH}_{3}\right)_{\mathrm{n}}$ to $\mathrm{Hg}_{2}(\mathrm{DME})_{\mathrm{n}}$, the vertical ionization threshold for $\mathrm{Hg}_{2}\left(\mathrm{NH}_{3}\right)_{\mathrm{n}}$ being close to the adiabatic ionization potential, while the dissociation of $\mathrm{Hg}_{3}^{+}(\mathrm{DME})_{\mathrm{n}}$ into $\mathrm{Hg}_{2}^{+}(\mathrm{DME})_{\mathrm{n}}$ suggests that the vertical and adiabatic potentials differ by more than one $\mathrm{eV}$. The fragmentation processes of these ionized clusters are relatively specific : $\mathrm{Hg}\left(\mathrm{NH}_{3}\right)_{\mathrm{n}}^{+}$and $\mathrm{Hg}(\mathrm{DME})_{\mathrm{n}}^{+}$clusters are mainly evaporating neutral molecules while the dissociation of $\mathrm{Hg}_{2}\left(\mathrm{NH}_{3}\right)_{\mathrm{n}}^{+}$yields to evaporation of free $\left(\mathrm{NH}_{3}\right)_{\mathrm{n}}^{+}$clusters. ${ }^{12}$

Solvation effects on the spectra as a function of the size of the cluster has been recently observed in the case of small $\mathrm{Hg}(\mathrm{Ar})_{n}$ clusters $(\mathrm{n}=1-4) .{ }^{20} \mathrm{We}$ have shown that the main spectroscopic difference between $\mathrm{HgAr}$ and $\mathrm{HgAr}_{\mathrm{n}}$ is a large blue shift of the whole spectrum as $n$ increases, the evolution towards the condensed phase occurs at very small size $(n \geq 4)$. Already for $n=4$ there is no more red shifted absorption, but the spectral shift towards the blue is not yet as large as the one observed for $\mathrm{Hg}$ in an Ar matrix $\left(1,250 \mathrm{~cm}^{-1}\right) .21,22$ 
In the present work, we have studied the solvation of $\mathrm{Hg}$ and $\mathrm{Hg}_{2}$ by polar molecules which are bound by van der Waals interaction in the ground state and which are quasi chemically bound in the excited state. Two types of solvents have been chosen:

1) water and ammonia which present strong hydrogen bonds. In this case the binding energy between two solvent molecules is larger than the binding energy of $\mathrm{Hg}$-molecule at least in the ground state.

2) dimethyl ether (DME) for which there is no hydrogen bonding. In this case the binding energy between two solvent molecules and the $\mathrm{Hg}$ molecule binding energy are comparable.

Finally, we have tried to explain the experimental data using the geometry of the clusters in the ground state determined by Molecular Dynamics calculations.

\section{EXPERIMENTAL}

$\mathrm{Hg}_{\mathrm{m}}(\mathrm{Mol})_{\mathrm{n}}$ clusters are formed in a pulsed expansion of rare gas. The experimental setup consists of two independently pumped vacuum chambers separated by a skimmer ( $3 \mathrm{~mm}$ diameter). Just before the pulsed valve (General Valve) a small reservoir containing mercury can be heated up to $150-200^{\circ} \mathrm{C}$, the valve being also heated in order to avoid condensation processes. The solvent molecules (water, ammonia or dimethylether) seeded in argon are expanded in the first chamber through a $100 \mu \mathrm{m}$ nozzle. The amount of water in the carrier gas is regulated by a by-pass allowing variation of water/Ar ratio between 0.1 and $1 \%$. Mixtures of ammonia/Ar or dimethylether/Ar (1-5\%) are used in the other cases.

In the second chamber a time-of-flight reflectron mass spectrometer (Jordan Co) is used for the detection of the ionized clusters. Two frequency doubled dye lasers pumped respectively with the second and third harmonic of a YAG laser (BM Industrie) are used to ionize the clusters. The ion signal is averaged by a 9400 LeCroy oscilloscope and recorded on a PC computer.

Two types of laser experiments have been carried out:

a) One-color two photon ionization through excited resonant states of the clusters in the spectral region close to the $\mathrm{Hg}\left({ }^{3} \mathrm{P}_{1} \leftarrow{ }^{1} \mathrm{~S}_{0}\right)$ transition is used to monitor excitation spectra of the lowest excited states correlating with $\mathrm{Hg}\left({ }^{3} \mathrm{P}_{1}\right)$ for the $\mathrm{Hg}(\mathrm{Mol})_{\mathrm{n}}$ or $\mathrm{Hg}_{2}\left(\mathrm{O}_{\mathrm{u}}^{+}\right.$or $\left.1_{\mathrm{u}}\right)$ for $\mathrm{Hg}_{2}(\mathrm{Mol})_{\mathrm{n}}$ clusters.

b) Two-color two photon ionization to measure ionization thresholds of the clusters. The two color method is also used whenever the ionization threshold cannot be reached by two photons of the same color.

The dissociation of the $\mathrm{Hg}\left({ }^{3} \mathrm{P}_{1}\right)$ 1-1 complexes with formation of the $\mathrm{Hg}\left({ }^{3} \mathrm{P}_{0}\right)$ atoms has been observed for $\mathrm{Hg}\left(\mathrm{NH}_{3}\right)$ and $\mathrm{Hg}\left(\mathrm{H}_{2} \mathrm{O}\right)^{14-16}$. In order to detect this process for $\mathrm{Hg}(\mathrm{DME})$ the following scheme has been used: the $\mathrm{Hg}\left({ }^{3} \mathrm{P}_{0}\right)$ issued from the dissociation after excitation of the complex by a first laser is ionized by the absorption of two photons of a second laser delayed in time ( $200 \mathrm{~ns})$ and resonant with the $6 \mathrm{~s} 8 \mathrm{~d}\left({ }^{3} \mathrm{D}\right) \leftarrow 6 \mathrm{~s} 6 \mathrm{p}\left({ }^{3} \mathrm{P}_{0}\right)$ transition at $237.9 \mathrm{~nm}$. 


\section{RESULTS}

\section{1) Excitation spectra of $\mathrm{Hg}(\text { Molecule })_{n}$}

The mass selected excitation spectra of $\mathrm{Hg}(\mathrm{Mol})_{\mathrm{n}}\left(\mathrm{Hg}\left(\mathrm{H}_{2} \mathrm{O}\right)_{\mathrm{n}}, \mathrm{Hg}\left(\mathrm{NH}_{3}\right)_{\mathrm{n}}\right.$ and $\left.\mathrm{Hg}(\mathrm{DME})_{\mathrm{n}}\right)$ clusters $(\mathrm{n}=1-10)$ in the $\left({ }^{3} \mathrm{P}_{1} \leftarrow{ }^{1} \mathrm{~S}_{0}\right) \mathrm{Hg}$ spectral range have been recorded. All the energies in the following are given relatively to the $\mathrm{Hg}\left({ }^{3} \mathrm{P}_{1} \leftarrow{ }^{1} \mathrm{~S}_{0}\right)$ transition.

Figure $2 \mathrm{~A}$ shows the $\operatorname{Hg}(\mathrm{DME})_{\mathrm{n}}$ spectra. The fluorescence excitation and the one color two photon ionization spectra of the 1-1 complex are nearly identical. They both show the same two broad bands. The absence of structures is probably due to the methyl groups which lead, as compared to $\mathrm{Hg}-\mathrm{H}_{2} \mathrm{O}$ (Figure 3A), to an increased number of vibrational modes and a lowering of the frequencies. Such a behavior was already observed for the B state of $\mathrm{Hg}\left(\mathrm{D}_{2} \mathrm{O}\right) \cdot{ }^{16}$ Moreover the spectral shifts are indicative of strong variations of geometries between the ground and excited state. Nevertheless in the $\mathrm{Hg}$-DME spectrum the two A and B electronic states similar to
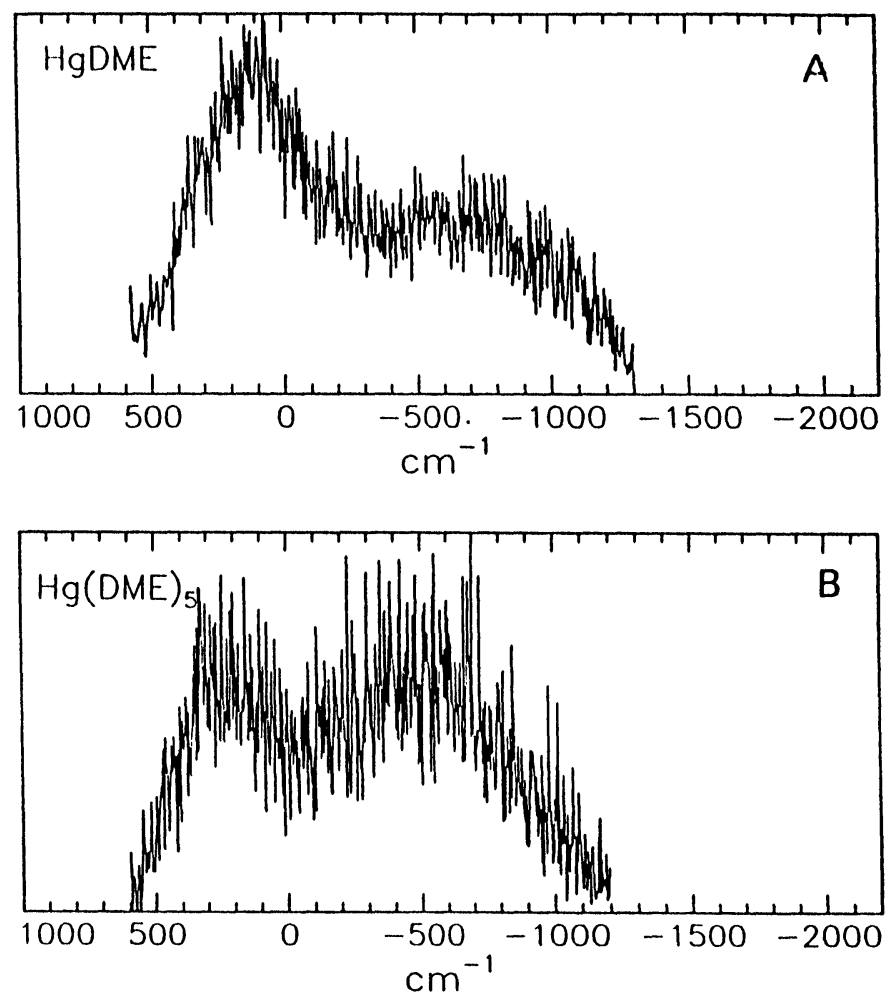

Figure 2 A) One color two photon Hg-DME Resonant Enhanced MultiPhoton Ionization (REMPI) spectrum in the $\mathrm{Hg}\left({ }^{3} \mathrm{P}_{1} \leftarrow{ }^{1} \mathrm{~S}_{0}\right)$ spectral region. The energies are given in respect with the $\mathrm{Hg}\left({ }^{3} \mathrm{P}_{1} \leftarrow{ }^{1} \mathrm{~S}_{0}\right)$ transition $\left(39,412 \mathrm{~cm}^{-1}\right)$.

B) One color two photon $\mathrm{Hg}(\mathrm{DME})_{5}$ REMPI spectrum in the $\mathrm{Hg}\left({ }^{3} \mathrm{P}_{1} \leftarrow{ }^{1} \mathrm{~S}_{0}\right)$ spectral region, The spectra for $n \subset(2,8)$ are very similar. 

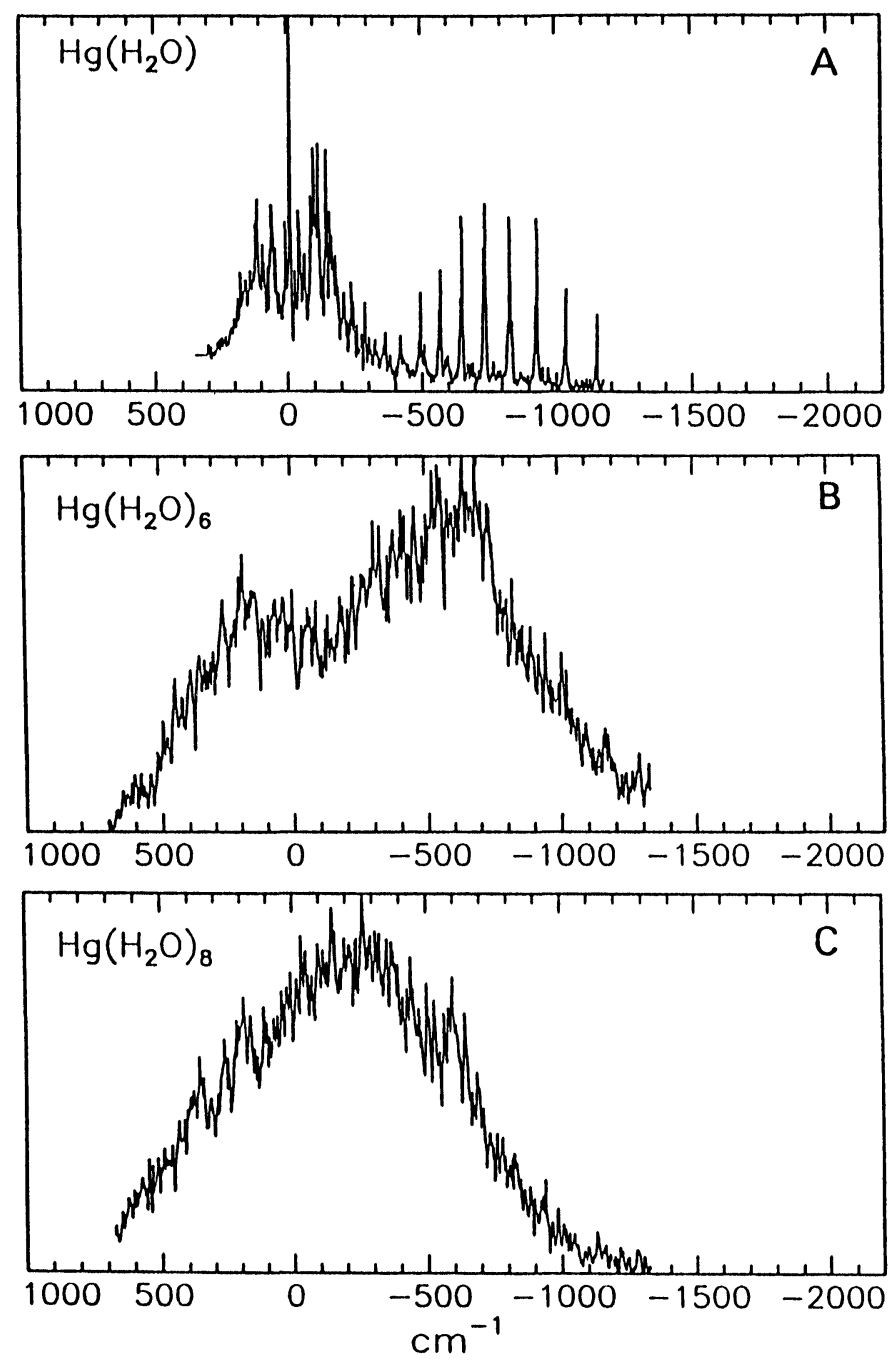

Figure 3 A) One color two photon $\mathrm{Hg}\left(\mathrm{H}_{2} \mathrm{O}\right)$ REMPI spectrum in the $\mathrm{Hg}\left({ }^{3} \mathrm{P}_{1} \leftarrow{ }^{1} \mathrm{~S}_{0}\right)$ spectral region: observation through ionization of $\operatorname{Hg}\left({ }^{3} \mathrm{P}_{0}\right)$ issued from the dissociation of the complex. The vibrational structure is similar to the one observed in reference (15).

B) One color two photon $\mathrm{Hg}\left(\mathrm{H}_{2} \mathrm{O}\right)_{6}$ REMPI spectrum in the $\mathrm{Hg}\left({ }^{3} \mathrm{P}_{1} \leftarrow{ }^{1} \mathrm{~S}_{0}\right)$ spectral region.

C) One color two photon $\mathrm{Hg}\left(\mathrm{H}_{2} \mathrm{O}\right)_{8}$ REMPI spectrum in the $\mathrm{Hg}\left({ }^{3} \mathrm{P}_{1} \leftarrow{ }^{1} \mathrm{~S}_{0}\right)$ spectral region. Although the spectrum lies in the same spectral region than the spectrum above $\left(\mathrm{Hg}\left(\mathrm{H}_{2} \mathrm{O}\right)_{6}\right)$, a narrowing of the absorption band is observed.

the well characterized states of $\mathrm{Hg}-\mathrm{H}_{2} \mathrm{O}$ and $\mathrm{Hg}-\mathrm{NH}_{3}$ can be distinguished. For larger clusters, as can be seen on Figure $2 \mathrm{~B}$, the excitation spectra are essentially the same i.e. the electronic structure of $\mathrm{Hg}^{*}(\mathrm{DME})_{\mathrm{n}}$ cluster is very similar to that of the 1-1 complex. No significant evolution in the shape of the spectra is observed when the cluster size increases. 
The spectra of $\mathrm{Hg}\left(\mathrm{NH}_{3}\right)_{n}$ are shown in Figure 4. In comparison with the spectrum of the 1-1 complex, 1-2 cluster is structureless, the absorption band shape of both complexes are similar, the $1-2$ complex being shifted to the blue by $\cong+500 \mathrm{~cm}^{-1}$ as compared to the $1-1$. For larger clusters $(n=3-10)$ no clear evolution in the shape of the spectra has been detected.
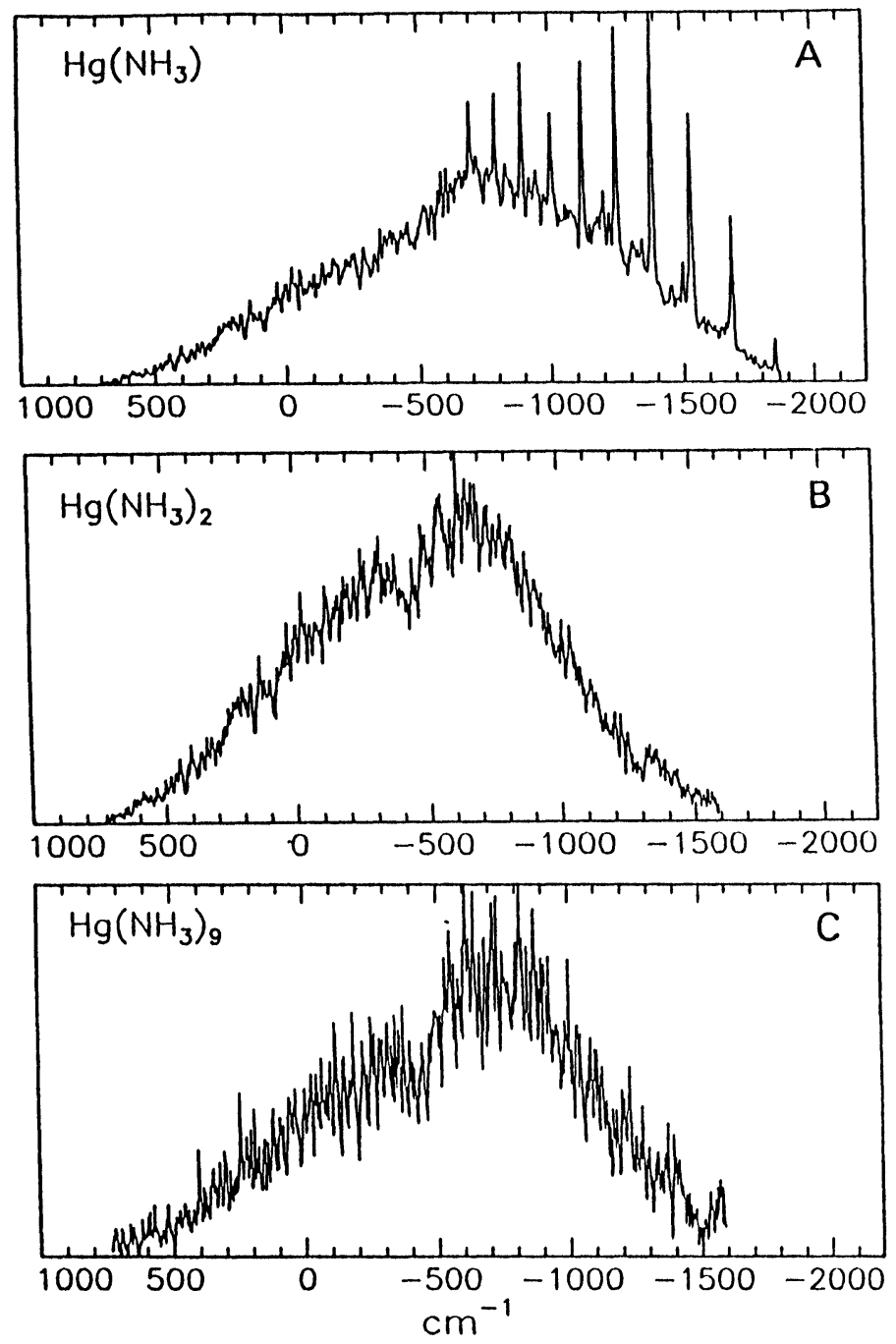

Figure 4 A) One color two photon $\mathrm{Hg}\left(\mathrm{NH}_{3}\right)$ REMPI spectrum in the $\mathrm{Hg}\left({ }^{3} \mathrm{P}_{1} \leftarrow{ }^{1} \mathrm{~S}_{0}\right)$ spectral region. The vibrational structure is similar to the one observed in reference (14). The broad band underlying the vibrational band is assigned to the dissociation $\mathrm{Hg}\left(\mathrm{NH}_{3}\right)_{\mathrm{n}}^{+} \rightarrow \mathrm{Hg}\left(\mathrm{NH}_{3}\right)^{+}+(\mathrm{n}-1) \mathrm{NH}_{3}$.

B) One color two photon $\mathrm{Hg}\left(\mathrm{NH}_{3}\right)_{2}$ REMPI spectrum in the $\mathrm{Hg}\left({ }^{3} \mathrm{P}_{1} \leftarrow{ }^{\prime} \mathrm{S}_{0}\right)$ spectral region. The similarity of this spectrum and the broad continuum of the figure above should be noticed.

C) One color two photon $\mathrm{Hg}\left(\mathrm{NH}_{3}\right)_{9}$ REMPI spectrum in the $\mathrm{Hg}\left({ }^{3} \mathrm{P}_{1} \leftarrow{ }^{1} \mathrm{~S}_{0}\right)$ spectral region. The spectrum is similar to the spectrum above $\left(\mathrm{Hg}\left(\mathrm{NH}_{3}\right)_{2}\right)$. 
The spectra of $\mathrm{Hg}\left(\mathrm{H}_{2} \mathrm{O}\right)_{\mathrm{n}}$ are shown in Figure 3. As in the case of ammonia, the spectra become broad but the two $\mathrm{A} \leftarrow \mathrm{X}$ and $\mathrm{B} \leftarrow \mathrm{X}$ transitions are observed. The spectrum of $\mathrm{Hg}\left(\mathrm{H}_{2} \mathrm{O}\right)_{2}$ is shifted by $\cong 300 \mathrm{~cm}^{-1}$ towards higher energy as compared to $\mathrm{HgH}_{2} \mathrm{O}$. The spectra do not change significantly until $\mathrm{n}=7$ (Figure 3B). Then for $n \geq 8$ (Figure 3C) a narrowing of the absorption feature leads to a spectrum which shows only one single band both $\mathrm{A} \leftarrow \mathrm{X}$ and $\mathrm{B} \leftarrow \mathrm{X}$ transitions being overlapped.

2) Excitation spectra of $\mathrm{Hg}_{2}(\mathrm{Mol})_{n}$

a) Excited state correlating to $\mathrm{Hg}_{2}\left(\mathrm{O}_{u}^{+}\right)$

All the $\mathrm{Hg}_{2}(\mathrm{Mol})_{\mathrm{n}}$ clusters show a relatively narrow (half width $\cong 500 \mathrm{~cm}^{-1}$ ) structureless absorption band in the $\mathrm{Hg}_{2}\left(\mathrm{O}_{\mathrm{u}}^{+}\right)$region.

For the water and ammonia clusters all the spectra are similar and situated in the $+600 \mathrm{~cm}^{-1}$ to $-600 \mathrm{~cm}^{-1}\left(\mathrm{Hg}_{2}\left(\mathrm{H}_{2} \mathrm{O}\right)_{\mathrm{n}}\right)$ and $+430 \mathrm{~cm}^{-1}$ to $-800 \mathrm{~cm}^{-1}\left(\mathrm{Hg}_{2}\left(\mathrm{NH}_{3}\right)_{\mathrm{n}}\right)$ spectral range (see Figure 1B).

For DME, the absorption of $\mathrm{Hg}_{2}(\mathrm{DME})$ lies in the $+200 \mathrm{~cm}^{-1}$ to $-600 \mathrm{~cm}^{-1}$ spectral range. When $n$ is increasing $(n \leq 6)$ we observe a progressive extension of the band towards the blue $\left(+600 \mathrm{~cm}^{-1}\right)$. For larger clusters the spectra do not evolve any more.

It can also be noticed that for these molecular $\mathrm{Hg}_{2}(\mathrm{Mol})_{\mathrm{n}}$ clusters the blue shift relative to free $\mathrm{Hg}_{2}\left(\mathrm{O}_{\mathrm{u}}^{+}\right)$is rather small $\left(\cong 0 \mathrm{~cm}^{-1}\right)$, much smaller than the shifts recorded for $\mathrm{Hg}_{2} \mathrm{Ar}_{\mathrm{n}}\left(+700 \mathrm{~cm}^{-1}\right)^{23}$.

\section{b) State correlating with $\mathrm{Hg}_{2}\left(1_{u}\right)$}

The absorption bands of $\mathrm{Hg}_{2}(\mathrm{Mol})_{\mathrm{n}}$ correlating to $\mathrm{Hg}_{2}\left(1_{\mathrm{u}}\right)$ are also broad and structureless and they present a maximum around $-2,000 \mathrm{~cm}^{-1}$ as in the $\mathrm{Hg}_{2}$ absorption band. However the absorption extends to lower energy as compared to $\mathrm{Hg}_{2}$. The absorption domains are the following:

$-\mathrm{Hg}_{2}\left(\mathrm{NH}_{3}\right)_{\mathrm{n}}:-1,000$ to $-7,000 \mathrm{~cm}^{-1}$ with an onset shifting to the red as the cluster size increases.

$-\mathrm{Hg}_{2}\left(\mathrm{H}_{2} \mathrm{O}\right)_{\mathrm{n}}:-1,000$ to $-4,300 \mathrm{~cm}^{-1}$.

$-\mathrm{Hg}_{2}(\mathrm{DME})_{\mathrm{n}}$ : $-1,000$ to $-7,700 \mathrm{~cm}^{-1}$.

\section{3) Dissociation channels}

Dissociation processes in the clusters may occur in the excited intermediate state or in the ionic state.

\section{a) dissociation in the excited state.}

Soep and co-workers have shown that in the excited state of the 1-1 complex the dissociation of $\mathrm{Hg}\left({ }^{3} \mathrm{P}_{1}\right)(\mathrm{Mol})$ can lead to the formation of $\mathrm{Hg}\left({ }^{3} \mathrm{P}_{0}\right)+\mathrm{Mol} .{ }^{14,15,16}$ This channel is in competition with the fluorescence decay. For symmetry reasons this 
channel is closed for $\mathrm{Hg}\left(\mathrm{Rare}\right.$ gas). ${ }^{24}$ For $\mathrm{HgNH}_{3}$ both channels, fluorescence and dissociation, are observed with a branching ratio depending on the symmetry of the excited vibrations. For $\mathrm{Hg}\left(\mathrm{H}_{2} \mathrm{O}\right)$ the dissociation channel becomes predominant and this complex does not fluoresce.

The $\operatorname{Hg}(\mathrm{DME})$ complex fluoresces with a decay time of about $400 \mathrm{~ns}$. Using the procedure described in the experimental part, we have detected the dissociation of the 1-1 complex into $\operatorname{Hg}\left({ }^{3} \mathrm{P}_{0}\right)$ in competition with the fluorescence channel. The dissociation channel appears when the complex is excited $520 \mathrm{~cm}^{-1}$ above the energy of the free $\mathrm{Hg}\left({ }^{3} \mathrm{P}_{0} \leftarrow{ }^{1} \mathrm{~S}_{0}\right)$ transition. Therefore the ground binding energy of the $\mathrm{Hg}$-DME complex is of the order of $500 \mathrm{~cm}^{-1}$ assuming that this dissociation pathway is open at the energetic threshold.

For larger $\mathrm{Hg}(\mathrm{Mol})_{\mathrm{n}}$ clusters the dissociation channel to ${ }^{3} \mathrm{P}_{0}$ is not observed. That point can be directly explained: the addition of new molecules leads to binding energies of the clusters which are greater than the energy difference between $\mathrm{Hg}\left({ }^{3} \mathrm{P}_{1}\right)$ and $\mathrm{Hg}\left({ }^{3} \mathrm{P}_{0}\right)$ which is $1,767 \mathrm{~cm}^{-1}$ and therefore the dissociation into $\mathrm{Hg}\left({ }^{3} \mathrm{P}_{0}\right)$ is not energetically allowed for the vibrational levels which can be accessed by FranckCondon transitions.

\section{B) dissociation in the ionic state.}

In the ionization process the cluster ion is obtained vibrationally excited since the Franck-Condon accessible region does not allow to reach the zero energy level of the ion. Moreover if the laser fluence is sufficiently high a third photon may be absorbed. The excess of energy in the ions generally leads to the break of the weakest bonds wherefrom informations on the structure of the clusters may be deduced. The $\mathrm{Hg}_{1,2}-(\mathrm{Mol})_{\mathrm{n}}^{+}$clusters may decay through different processes:

[1]-evaporation

$$
\mathrm{Hg}_{1,2}(\mathrm{Mol})_{\mathrm{n}}^{+} \rightarrow \mathrm{Hg}_{1,2}(\mathrm{Mol})_{\mathrm{n}-\mathrm{x}}^{+}+\mathrm{x} \mathrm{Mol}
$$

[2]- "ionization transfer"

$$
\mathrm{Hg}_{1,2}(\mathrm{Mol})_{\mathrm{n}}^{+} \rightarrow \mathrm{Hg}_{1,2}+(\mathrm{Mol})_{\mathrm{n}}^{+}
$$

For $\mathrm{Hg}_{2}(\mathrm{Mol})_{\mathrm{n}}$ a third channel can also be observed:

[3]- $\mathrm{Hg}-\mathrm{Hg}$ bond rupture

$$
\mathrm{Hg}_{2}(\mathrm{Mol})_{\mathrm{n}}^{+} \rightarrow \mathrm{Hg}(\mathrm{Mol})_{\mathrm{x}}^{+}+\mathrm{Hg}(\mathrm{Mol})_{\mathrm{y}}+(\mathrm{n}-\mathrm{x}-\mathrm{y}) \mathrm{Mol}
$$

\section{a) Dissociation of $\mathrm{Hg}(\mathrm{Mol})_{n}$}

For these clusters the evaporation process [1] seems to be predominant. For example a broad absorption band in the structured excitation spectra of the 1-1 complexes $\left(\mathrm{Hg}-\mathrm{NH}_{3}, \mathrm{Hg}-\mathrm{H}_{2} \mathrm{O}\right)$, whose shape corresponds to spectra of larger clusters, is observed when the amount of larger clusters in the jet is increased. This continuum is thus assigned to the dissociation of $\mathrm{Hg}(\mathrm{Mol})_{2}^{+}$into $\mathrm{Hg}(\mathrm{Mol})^{+}$. For $\mathrm{Hg}$-DME and larger $\mathrm{Hg}\left(\mathrm{NH}_{3}\right)_{\mathrm{n}}$ and $\mathrm{Hg}\left(\mathrm{H}_{2} \mathrm{O}\right)_{\mathrm{n}}$ clusters the spectral shapes do not change so much with 
$\mathrm{n}$; it is therefore difficult to estimate the importance of this dissociation channel. The $\mathrm{Hg}^{+}$fragment is never observed in these experiments because the ionization potential of mercury is higher than the energy of two photons.

The process leading to the loss of mercury with ionization transfer [2] is not observed for $\mathrm{Hg}(\mathrm{Mol})_{\mathrm{n}}$ clusters.

\section{b) $\mathrm{Hg}_{2}(\mathrm{Mol})_{n}$}

The dissociation paths for clusters involving mercury dimer are rather different. The evaporation process [1] can be studied only if one can excite the $\mathrm{Hg}_{2}(\mathrm{Mol})_{\mathrm{n}}$ clusters without exciting $\mathrm{Hg}_{2}(\mathrm{Mol})_{\mathrm{n}-1}$. Since it is not the case, this channel cannot be characterized.

The second process [2] is important as it can be deduced from the presence in the mass spectra of peaks corresponding to $(\mathrm{Mol})_{\mathrm{x}}^{+}$(Figure 5A). The REMPI spectra of $(\mathrm{Mol})_{\mathrm{x}}^{+}$are the same as those of $\mathrm{Hg}_{2}(\mathrm{Mol})_{\mathrm{n}}^{+}$. This channel is observed for water and ammonia but not for $\mathrm{Hg}_{2}(\mathrm{DME})_{\mathrm{n}}$ (Figure 5 b). This dissociation is generally followed by a rearrangement of the ionized molecular clusters with a loss of neutral fragments giving rise to new masses:

$$
\begin{gathered}
\left(\mathrm{H}_{2} \mathrm{O}\right)_{\mathrm{n}}^{+} \rightarrow \mathrm{H}_{3} \mathrm{O}^{+}\left(\mathrm{H}_{2} \mathrm{O}\right)_{\mathrm{n}-2}+\mathrm{OH}^{\cdot} \\
\text { or }\left(\mathrm{NH}_{3}\right)_{n}^{+} \rightarrow \mathrm{NH}_{4}^{+}\left(\mathrm{NH}_{3}\right)_{\mathrm{n}-2}+\mathrm{NH}_{2} .
\end{gathered}
$$

The occurrence of a third dissociation channel [3] (rupture of the $\mathrm{Hg}-\mathrm{Hg}$ bond) can be evidenced only in the energy domain where $\mathrm{Hg}(\mathrm{Mol})_{\mathrm{n}-\mathrm{x}}^{+}$cannot be produced from $\mathrm{Hg}(\mathrm{Mol})_{\mathrm{n}}$ i.e. where $\mathrm{Hg}(\mathrm{Mol})_{\mathrm{n}}$ do not absorb $(\lambda \geqslant 270 \mathrm{~nm})$. This dissociation is observed for $\mathrm{Hg}_{2}\left(\mathrm{H}_{2} \mathrm{O}\right)_{\mathrm{n}}^{+}, \mathrm{Hg}_{2}\left(\mathrm{NH}_{3}\right)_{\mathrm{n}}^{+}$and $\mathrm{Hg}_{2}(\mathrm{DME})_{\mathrm{n}}^{+}$whenever the energy of the first photon is larger than a threshold which corresponds to $-3,700 \mathrm{~cm}^{-1},-5,500 \mathrm{~cm}^{-1}$ and $-6,600 \mathrm{~cm}^{-1}$ respectively.

\section{GROUND STATE GEOMETRIES OF $\mathrm{Hg}(\mathrm{Mol})_{\mathrm{n}}$}

In the previous paper on $\operatorname{HgAr}_{n}$ we have shown that the variation of the spectral shape of the excitation spectrum as $n$ increases is closely related to the ground state geometry of the $\mathrm{HgAr}_{\mathrm{n}}$ clusters. In order to discuss this relation in the case of the $\mathrm{Hg}_{\mathrm{m}}(\mathrm{Mol})_{\mathrm{n}}$ spectra, the ground state cluster geometries have been calculated.

\section{1) Method}

Molecular Dynamics simulations have been performed in order to determine the $\mathrm{Hg}(\mathrm{Mol})_{\mathrm{n}}$ equilibrium geometries in the ground state.

In our calculations, the potential surface is explored using classical dynamics and the minima of the potential energy surface are found using the following proce- 

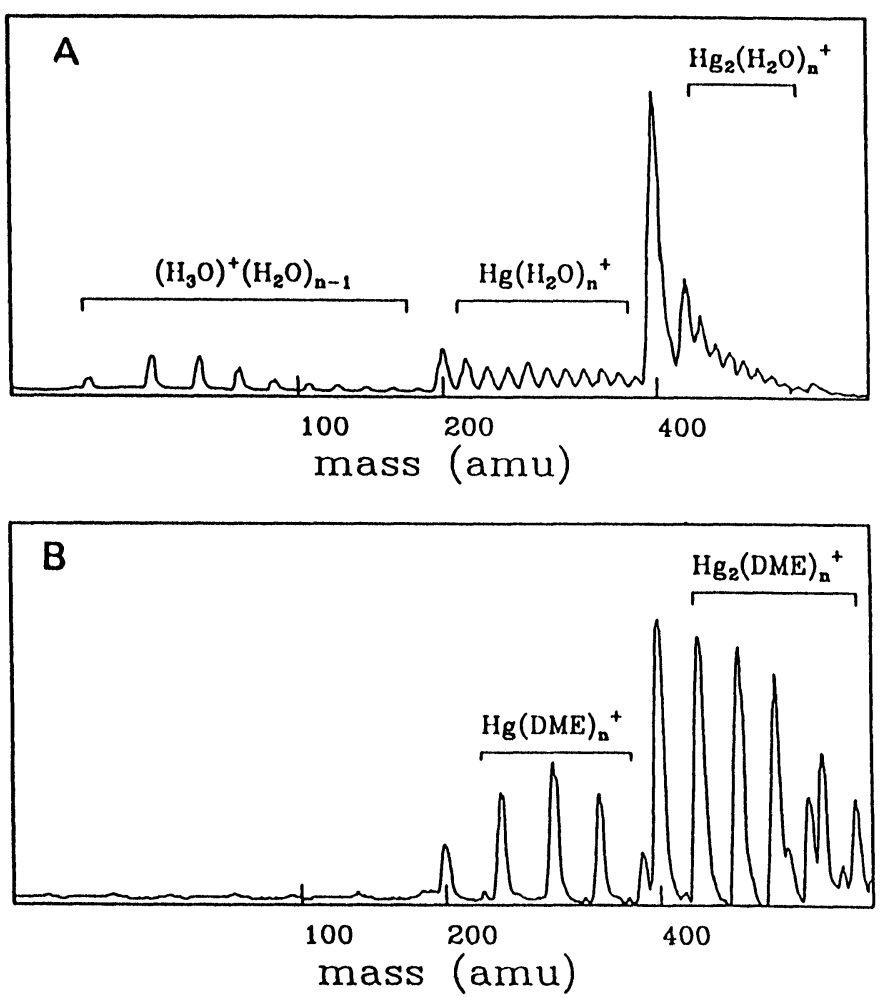

Figure 5 A) Time of flight mass spectrum observed when the $\mathrm{Hg}_{2}\left(\mathrm{H}_{2} \mathrm{O}\right)_{n}$ clusters are excited at $39,400 \mathrm{~cm}^{-1}$. The dissociation channel: $\mathrm{Hg}_{2}\left(\mathrm{H}_{2} \mathrm{O}\right)_{\mathrm{n}}^{+} \rightarrow \mathrm{Hg}_{2}+\left(\mathrm{H}_{2} \mathrm{O}\right)_{n}^{+} \rightarrow \mathrm{Hg}_{2}+\mathrm{H}_{3} \mathrm{O}^{+}\left(\mathrm{H}_{2} \mathrm{O}\right)_{\mathrm{n}-2}+\mathrm{OH}^{\cdot}$ is characterized because the spectrum recorded at the $\mathrm{H}_{3} \mathrm{O}^{+}\left(\mathrm{H}_{2} \mathrm{O}\right)_{n-2}$ mass is similar to the spectrum recorded at the mass of $\mathrm{Hg}_{2}\left(\mathrm{H}_{2} \mathrm{O}\right)_{\mathrm{n}}^{+}$.

B) Time of flight mass spectrum observed when the $\mathrm{Hg}_{2}(\mathrm{DME})_{\mathrm{n}}$ clusters are excited at $32,400 \mathrm{~cm}^{-1}$.The dissociation channel $\mathrm{Hg}_{2}(\mathrm{DME})_{\mathrm{n}}^{+} \rightarrow \mathrm{Hg}(\mathrm{DME})_{\mathrm{n}}^{+}+\mathrm{Hg}(\mathrm{DME})_{\mathrm{y}}$ is observed: mass peaks corresponding to $\mathrm{Hg}(\mathrm{DME})_{\mathrm{n}}^{+}$appear in these spectral range where these neutral clusters do not absorb. The dissociation channel $\mathrm{Hg}_{2}(\mathrm{DME})_{\mathrm{n}}^{+} \rightarrow \mathrm{Hg}_{2}+(\mathrm{DME})_{\mathrm{n}}^{+}$is not observed in the $\mathrm{Hg}\left({ }^{3} \mathrm{P}_{1} \leftarrow{ }^{1} \mathrm{~S}_{0}\right)$ spectral region $\left(+1,000 \mathrm{~cm}^{-1}\right.$ to $\left.-3,000 \mathrm{~cm}^{-1}\right)$.

dure. ${ }^{24,25}$ Starting from a particular isomer, kinetic energy is increased to about $30 \%$ of the binding energy in order to overcome the barriers between the different isomers without evaporating solvent molecules. After a delay of 10 to $20 \mathrm{ps}$, during which the energy is shared among all the degrees of freedom, a quench procedure is performed every one or two ps: periodically along the trajectory, a quenching force is added in order to cool the cluster which is then trapped in the neighboring well of the surface. This method allows to explore a whole significant set of minima. In fact, the dynamical quench allows the clusters to be trapped only in minima that correspond to the largest attraction valleys. The appearance frequency of an isomer in the quench procedure may give an idea of which isomers are preferentially populated in the expansion. 


\section{1 a) Interaction potentials}

The potentials used in this work are based on the assumption that the total interaction potential surface results from the sum of two body interactions. In the work on $\mathrm{Hg}(\mathrm{Ar})_{\mathrm{n}}$ clusters previously developed we had only to consider atom-atom interactions. In the case of molecular clusters, the van der Waals intermolecular interactions are small as compared to the chemical binding energies in the molecules. Deformations of the molecules due to the complexation are neglected, this seems reasonable in the ground state since the $\mathrm{Hg}-\mathrm{Mol}$ interaction is very small (van der Waals). Such approximations are certainly not valid for the excited state and no attempt has been made to calculate the excited states.

Two types of interaction potentials are needed: $\mathrm{Hg}-\mathrm{Molecule}$ and MoleculeMolecule.

\section{Hg-Molecule:}

As in the previous work, ${ }^{20}$ this potential is derived from the spectroscopy of the 1-1 complex which gives the binding energy, equilibrium distance, vibrational frequency. ${ }^{14,15,16}$ A Morse potential is then derived to represent the $\mathrm{Hg}-\mathrm{H}_{2} \mathrm{O}$ or the $\mathrm{Hg}$ $\mathrm{NH}_{3}$ interaction along the $\mathrm{Hg}-\mathrm{O}$ and $\mathrm{Hg}-\mathrm{N}$ coordinate. The spectroscopy of these complexes also showed that the ligands cannot freely rotate around the $\mathrm{Hg}-(\mathrm{O} / \mathrm{N})$ axis. For water this barrier has been evaluated to be around $20 \mathrm{~cm}^{-1}$. For $\mathrm{Hg}-\mathrm{NH}_{3}$ this barrier is larger due to the pyramidal structure of ammonia. As the whole potential surface is represented by a sum of Morse potentials, these barriers have been reproduced by adding an $\mathrm{Hg}-\mathrm{H}$ Morse potential derived from spectrum of the $\mathrm{HgH}_{2}$ complex. ${ }^{27}$

Due to the lack of structure in the HgDME spectrum, no experimental data are available for the evaluation of the $\mathrm{Hg}-\mathrm{DME}$ interaction. In a crude approximation this potential has been built as a sum of an $\mathrm{Hg}-\mathrm{O}$ Morse potential which is the same as for water and two $\mathrm{Hg}-\mathrm{CH}_{3}$ potentials, derived from the $\mathrm{HgCH}_{4}$ spectrum, ${ }^{28}$ centered on the $\mathrm{C}$ atom. This leads to a binding energy of $720 \mathrm{~cm}^{-1}$ for $\mathrm{Hg}-\mathrm{DME}$.

\section{Molecule-Molecule}

The $\mathrm{H}_{2} \mathrm{O}-\mathrm{H}_{2} \mathrm{O}$ and $\mathrm{NH}_{3}-\mathrm{NH}_{3}$ interaction potentials have been found in the literature. For water, we use the Watt's RWK2 potential ${ }^{29}$ which presents the advantage to reproduce fairly well the dissymetrical structure of the water dimer $^{30}$ in which one $\mathrm{H}$ of the first molecule is pointing towards the $\mathrm{O}$ of the other molecule and giving a binding energy of $2,065 \mathrm{~cm}^{-1}$ in good agreement with the experimental value of $1,800 \mathrm{~cm}^{-1} .31$

For ammonia the potential which has been used is the same as that used by Hertel and co-workers for the calculation of the geometry of the ammonia clusters. ${ }^{32}$ It consists in an atom-atom potential whose parameters are optimized in order to fit ab initio calculations ${ }^{33}$ which are reproducing the structure of the ammonia dimer which has been determined experimentally ${ }^{34-39}$ This potential gives a binding energy 
of $1,234 \mathrm{~cm}^{-1}$ for the dimer with an $\mathrm{N}-\mathrm{N}$ distance of $3.38 \AA$ in good agreement with the experimental value.

All the parameters used for the different Morse potential are given in table 1.

For DME-DME the geometry and binding energy $\left(650 \mathrm{~cm}^{-1}\right)$ have been determined using Scheraga's atom-atom approximation. ${ }^{40,41}$

\section{1b) Definition of the molecular solvation of mercury}

One purpose of this work is to try to define criteria of solvation of mercury by molecules for cluster sizes where the solvation shell is not yet complete. The question is more likely: does the metal strongly or slightly perturb the molecular cluster? Does the atom sit on the cluster or does it go inside the molecular cluster?

Calculations give an idea how to solve this problem and many criteria can be used to determine if the atom sits on or within the cluster. Among all the isomer calculated, only those which have the highest binding energy will be obtained in the jet and will be considered in the following discussion.

(i) After geometry optimization of the metal-molecule cluster, the $\mathrm{Hg}$ is removed and the energy of the remaining molecular cluster is optimized. If the metalmolecules binding is larger than the Mol-Mol interaction, deformations are important and the metal is nested into the cluster. At the opposite, if the metal-molecule interaction is weaker than the Mol-Mol interaction the metal does not perturb the molecular cluster and the metal stays on the surface of the cluster.

(ii) One can calculate the distance between the metal and the center of mass of the molecular cluster. If the metal is inside the molecular cluster this distance should be much shorter than the $\mathrm{Hg}-\mathrm{Mol}$ distance in the 1-1 complex. At the opposite if the metal sits on the molecular cluster this distance should be larger than the Hg-Mol distance.

(iii) When many isomers are found one can see the ones where the metal is the most "solvated" by counting how many Mol-Mol bonds in the molecular cluster have been dissociating and how many $\mathrm{Hg}-\mathrm{Mol}$ have been built when the $\mathrm{Hg}$ atom is added to the free molecular cluster. For the metal-Mol interaction, for water and ammonia the $\mathrm{Hg}-(\mathrm{O} / \mathrm{N})$ distance is the reference and one consider that there is a metal-Mol bond if the distance in the cluster is not larger than 1.2 time this reference. This is reasonable since in the construction of the potential it is this interaction which determines the geometry for the 1-1 complex (equilibrium distance). For the same reason for $\mathrm{DME}$, this geometry depends on the sum of three interactions $(\mathrm{Hg}-\mathrm{O}$ and twice $\mathrm{Hg}-\mathrm{CH}_{3}$ ), then the reference distance must be $\mathrm{Hg}-\mathrm{DME}$ center of mass. For molecular clusters, we have to take into account the distance between the centers of mass and the relative orientation of the molecules.

\section{2) Structure of $\mathrm{Hg}(\mathrm{Mol})_{n}$}

In this paragraph the geometries of the $\mathrm{Hg}(\mathrm{Mol})_{\mathrm{n}}$ clusters are presented and we will discuss the "solvation" of the mercury atom when the size is increasing. The binding 
Table I Potential used for the ground state geometry calculations.

\section{Mercury Molecule Morse potential.}

Morse Potential V(R) $=$ De $\left[1-\exp (-\alpha e(R-R e)]^{2}-\mathrm{De}\right.$

\begin{tabular}{|c|c|c|c|}
\hline & $\begin{array}{l}D e \\
\left(\mathrm{~cm}^{-1}\right)\end{array}$ & $\begin{array}{l}\alpha e \\
\left(A^{-1}\right)\end{array}$ & $\begin{array}{l}\text { Re } \\
\AA\end{array}$ \\
\hline $\mathrm{Hg}-\mathrm{O}_{\left(\mathrm{H}_{2} \mathrm{O}\right)}$ & 320 & 1.106 & 3.4 \\
\hline $\mathrm{Hg}-\mathrm{H}_{\left(\mathrm{NH}_{3}\right)}$ & 260 & 1.495 & 3.30 \\
\hline $\mathrm{Hg}-\mathrm{H}$ & 1.25 & 0.68 & 4.5 \\
\hline $\mathrm{Hg}-$ Methyl & 179 & 1.174 & 4 \\
\hline
\end{tabular}

$\mathrm{NH}_{3}-\mathrm{NH}_{3}$ potential

$\operatorname{Vij}(R)=\operatorname{Dij} \exp (-B i j R)+\frac{\text { qiqj }}{R}+\frac{C i j}{R^{6}} \times F i j(R)$

with Fij $(\mathrm{R})=\exp \left[-\left(1.28 \frac{\mathrm{c}}{\mathrm{Rij}} \mathrm{R}-1\right)^{2}\right]$ for $\mathrm{R} \leq 1.28 \AA$

\begin{tabular}{|l|l|l|l|l|}
\hline & $D i j\left(\mathrm{~cm}^{-1}\right)$ & $B i j\left(\AA^{-1}\right)$ & $C i j^{6}\left(\mathrm{~cm}^{-1} \AA^{6}\right)$ & $\mathrm{R}_{\mathrm{i}}^{\mathrm{c}} j(\AA)$ \\
\hline $\mathrm{N}-\mathrm{N}$ & $1.168 \times 10^{7}$ & 2.996 & $5.356 \times 10^{5}$ & 4.21 \\
\hline $\mathrm{N}-\mathrm{H}$ & $1.013 \times 10^{6}$ & 3.437 & $1.033 \times 10^{5}$ & 3.73 \\
\hline $\mathrm{H}-\mathrm{H}$ & $2.494 \times 10^{5}$ & 3.330 & $1.995 \times 10^{4}$ & 3.13 \\
\hline
\end{tabular}

and $\mathrm{q}_{\mathrm{N}}=-1.3197 \mathrm{C}$

$$
\mathrm{q}_{\mathrm{H}}=0.4399 \mathrm{C}
$$

\section{DME-DME potential}

$$
\mathrm{Vij}=\frac{\mathrm{Aij}}{\mathrm{R}^{12}}-\frac{\mathrm{Cij}}{\mathrm{R}^{6}}+\frac{\text { qiqj }}{2 \mathrm{R}}
$$

\begin{tabular}{|c|c|c|}
\hline & $C i j\left(\mathrm{~cm}^{-1} \AA^{6}\right)$ & $A i j\left(\mathrm{~cm}^{-1} \AA^{12}\right)$ \\
\hline O-O & $9.11 \times 10^{4}$ & $5.27 \times 10^{7}$ \\
\hline O-C & $1.17 \times 10^{5}$ & $1.45 \times 10^{8}$ \\
\hline O-H & $3.79 \times 10^{4}$ & $1.62 \times 10^{7}$ \\
\hline C-C & $1.55 \times 10^{5}$ & $3.80 \times 10^{8}$ \\
\hline C-H & $5.27 \times 10^{4}$ & $5.01 \times 10^{7}$ \\
\hline H-H & $1.91 \times 10^{4}$ & $5.91 \times 10^{6}$ \\
\hline
\end{tabular}


energies are given in table II relatively to the molecules without interactions (internal energies of the molecular species are not included in this value).

Table II Calculated binding energies of the ground state clusters.

\begin{tabular}{llclc}
\hline Molecule & $($ Mol $) n$ & Binding energy $\left(\mathrm{cm}^{-1}\right)$ & $\mathrm{Hg}(\mathrm{Mol}) n$ & Binding energy $\left(\mathrm{cm}^{-1}\right)$ \\
\hline $\mathrm{NH}_{3}$ & $\left(\mathrm{NH}_{3}\right)_{2}$ & 1234 & $\mathrm{Hg}\left(\mathrm{NH}_{3}\right)_{2}$ & 1685 \\
& $\left(\mathrm{NH}_{3}\right)_{2}$ & 3596 & $\mathrm{Hg}\left(\mathrm{NH}_{3}\right)_{3}$ & 4253 \\
& $\left(\mathrm{NH}_{3}\right)_{4}$ & 5659 & $\mathrm{Hg}\left(\mathrm{NH}_{3}\right)_{4}$ & 6541 \\
& $\left(\mathrm{NH}_{3}\right)_{8}$ & 13287 & $\mathrm{Hg}\left(\mathrm{NH}_{3}\right)_{8}$ & 14588 \\
$\mathrm{H}_{2} \mathrm{O}$ & $\left(\mathrm{H}_{2} \mathrm{O}\right)_{2}$ & 2065 & & \\
& $\left(\mathrm{H}_{2} \mathrm{O}\right)_{3}$ & 5110 & $\mathrm{Hg}\left(\mathrm{H}_{2} \mathrm{O}\right)_{2}$ & 2691 \\
& $\left(\mathrm{H}_{2} \mathrm{O}\right)_{4}$ & 9122 & $\mathrm{Hg}\left(\mathrm{H}_{2} \mathrm{O}\right)_{3}$ & 6051 \\
& $\left(\mathrm{H}_{2} \mathrm{O}\right)_{8}$ & 24587 & $\mathrm{Hg}\left(\mathrm{H}_{2} \mathrm{O}\right)_{4}$ & 10369 \\
& & $\mathrm{Hg}\left(\mathrm{H}_{2} \mathrm{O}\right)_{8}$ & 25814 \\
\hline
\end{tabular}

2 a) $\mathrm{Hg}\left(\mathrm{H}_{2} \mathrm{O}\right)_{n}$

The geometry of the small $\mathrm{Hg}\left(\mathrm{H}_{2} \mathrm{O}\right)_{n}=1-4$ clusters are represented in Figure 6 . These clusters show the same characteristics:

- the presence of the mercury does not change significantly the structure of the pure water clusters. The mercury atom lies at the surface of the cluster; the most stable structures are obtained when the metal interacts with a maximum number of water molecules.

Our calculations also show that for these clusters which can be considered as a "plane" of water molecules with a metal atom placed above this plane, the more strongly bound clusters are those with the highest symmetry. This can be understood since water and small water clusters are planar, the approach of the metal on highest symmetry axis is not hindered by the $\mathrm{H}$ atoms.

Larger $\mathrm{Hg}\left(\mathrm{H}_{2} \mathrm{O}\right)_{n}>4$ have nearly the same kind of structure: however the number of isomers increases (this is also true for pure water clusters). The mercury always stays at the surface of these water clusters as it can be seen in the Figure 6 for example for $\mathrm{n}=8$ (binding energy $=25,814 \mathrm{~cm}^{-1}$ ). In the molecular simulation one can find some stable loose structures where the $\mathrm{Hg}$ seems to be solvated but their energies are a lot higher than the most stable ones.

\section{2 b) $\mathrm{Hg}\left(\mathrm{NH}_{3}\right)_{n}$}

Small $\mathrm{Hg}\left(\mathrm{NH}_{3}\right)_{\mathrm{n}} \leq 4$ are not very different from $\mathrm{Hg}\left(\mathrm{H}_{2} \mathrm{O}\right)_{\mathrm{n}}$ clusters. Mercury is bound to ammonia clusters which are practically unperturbed (see Figure 7).

However, the most symmetrical isomers are not the only one populated in the quench procedure. This can be understood as an effect of the ammonia tridimensional structure. In the smallest clusters, the $\mathrm{N}$ atoms lie in a planar structure, but some hydrogen atoms point out this plane and can hinder the approach of the mercury atom on the symmetry axis. 


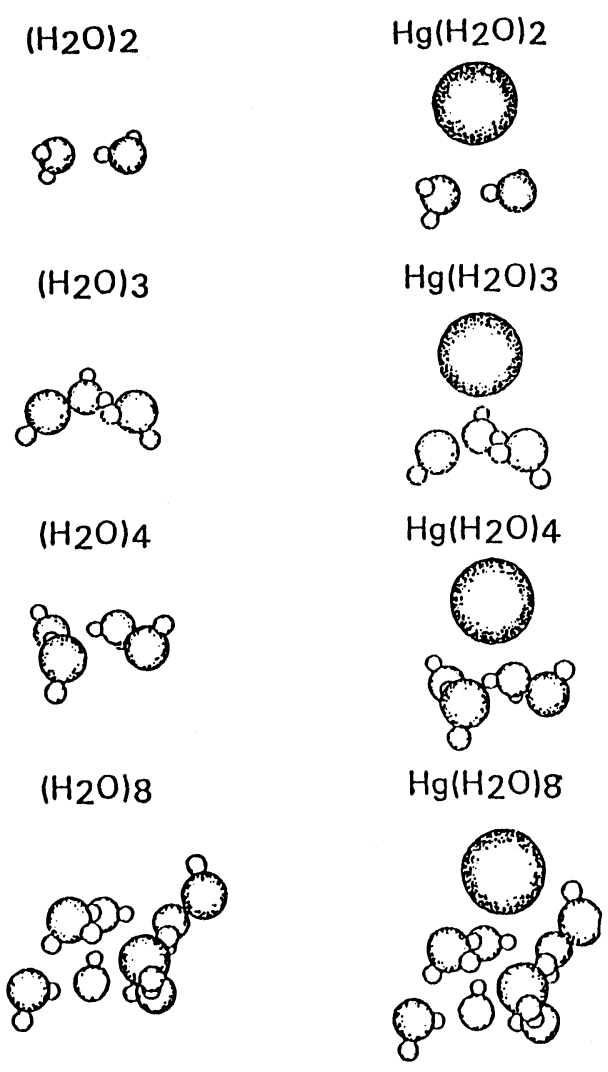

Figure 6 Most stable calculated structures of $\left(\mathrm{H}_{2} \mathrm{O}\right)_{n}$ and $\mathrm{Hg}\left(\mathrm{H}_{2} \mathrm{O}\right)_{\mathrm{n}}$ clusters. The $\mathrm{Hg}$ atom sits on the surface of the $\left(\mathrm{H}_{2} \mathrm{O}\right)_{n}$ cluster.

Larger $\mathrm{Hg}\left(\mathrm{NH}_{3}\right)_{\mathrm{n}}$ clusters are not very different from water clusters. The mercury atom is always found at the surface of the cluster. The study of the $\mathrm{Hg}\left(\mathrm{NH}_{3}\right)_{8}$ clusters leads to the following comments:

— the most stable isomer consists in a $\left(\mathrm{NH}_{3}\right)_{8}$ cluster $\left(12 \mathrm{NH}_{3}-\mathrm{NH}_{3}\right.$ bonds $)$ and a mercury bound by $4 \mathrm{Hg}-\mathrm{NH}_{3}$ bonds (binding energy $=14,588 \mathrm{~cm}^{-1}$ ).

- however many isomers with nearly the same binding energies are calculated. In some of them the mercury induces a perturbation of the initial pure ammonia structure leading sometimes in a loss of 300 to $400 \mathrm{~cm}^{-1}$ of their binding energies in order to favor a maximum of $\mathrm{Hg}-\mathrm{NH}_{3}$ (up to 7 or 8) bonds. It results that for ammonia, in some isomers the $\mathrm{Hg}$ atom can begin to disturb the molecular cluster but even in these cases distance between the centers of masses is still larger than $2 \AA$ and the $\mathrm{Hg}$ atom sit on a disturbed surface. 


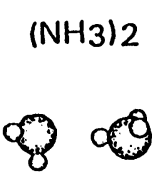

$\left(\mathrm{NH}_{3}\right)_{3}$

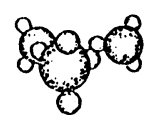

$\left(\mathrm{NH}_{3}\right)_{4}$

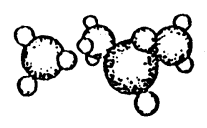

$\left(\mathrm{NH}_{3}\right)_{8}$

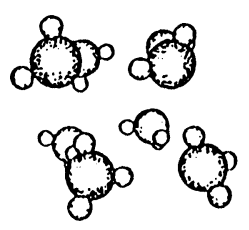

$\mathrm{Hg}\left(\mathrm{NH}_{3}\right) 2$

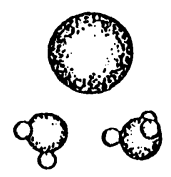

$\mathrm{Hg}\left(\mathrm{NH}_{3}\right)_{3}$

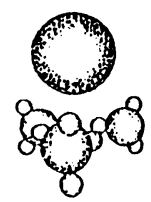

$\mathrm{Hg}(\mathrm{NH} 3)_{4}$
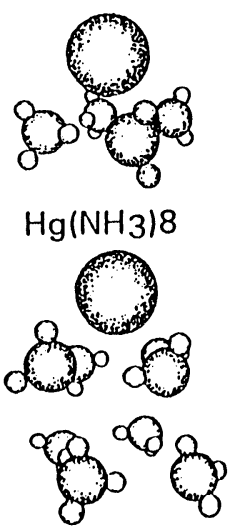

Figure 7 Most stable calculated structures of $\left(\mathrm{NH}_{3}\right)_{\mathrm{n}}$ and $\mathrm{Hg}\left(\mathrm{NH}_{3}\right)_{\mathrm{n}}$ clusters. The $\mathrm{Hg}$ atom sits on the surface of the $\left(\mathrm{NH}_{3}\right)_{\mathrm{n}}$ cluster.

\section{2c) $\mathrm{Hg}(D M E)_{n}$}

$\mathrm{Hg}(\mathrm{DME})_{\mathrm{n}}$ clusters cannot be studied as precisely as the previous ones because the precision on the interaction potentials is poor. However, for $\operatorname{Hg}(\mathrm{DME})_{\mathrm{n}}=1-4$ some points can be emphasized. The main difference with water or ammonia is the flexibility of the clusters even for small sizes leading to several isomers. For $\operatorname{Hg}(\mathrm{DME})_{\mathrm{n}}=2,3$ similar results as before are found: the presence of mercury does not perturb the free DME clusters. However for $\mathrm{n}=4$, for the most stable isomer (binding energy $=4,795 \mathrm{~cm}^{-1}$ ) the presence of the mercury atom leads to a destabilisation of the binding energy between the DME molecules as compared to this binding energy in the pure tetramer by about $350 \mathrm{~cm}^{-1}$ i.e. half the binding energy between DME-DME. The insertion of the mercury in the solvent cluster (see Figure 8) is also characterized by the fact that one DME-DME bond changes from $4.8 \AA \AA$ to $6.7 \AA$. 
(DME)4

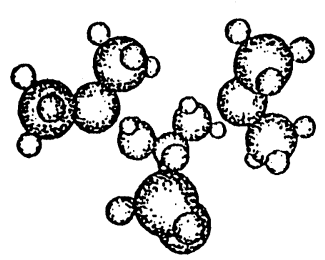

$\mathrm{Hg}(\mathrm{DME}) 4$

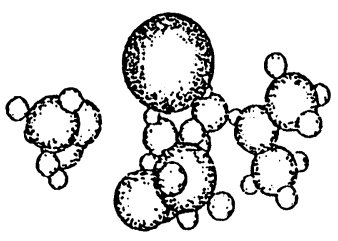

Figure 8 Most stable calculated structures of $(\mathrm{DME})_{4}$ and $\mathrm{Hg}(\mathrm{DME})_{4}$ clusters. The $\mathrm{Hg}$ atom inserts into the $(\mathrm{DME})_{4}$ cluster.

Unfortunately, the poor precision on the potentials and the rapid increase of the number of interactions with the number of DME molecule did not allow us to perform accurate calculations for larger clusters.

\section{3) Conclusion}

From these calculations it seems that for $\mathrm{H}_{2} \mathrm{O}$ and $\mathrm{NH}_{3}$ the mercury atom sits on the molecular cluster whereas in the case of DME the $\mathrm{Hg}$ is more likely to be nested within the cluster.

\section{DISCUSSION}

In our recent work on $\mathrm{Hg}(\mathrm{Ar})_{n}$ clusters ${ }^{20}$ we have shown that the interactions between rare gas and the metal are essentially van der Waals i.e. weak and governed by the minimization of the repulsion forces. It results that simple additivity rules even for excited states can be applied. The small deviations to these rules observed for argon do not play a major role. Using these assumptions we could explain the overall blue shift of the spectra in the $\mathrm{Hg}(\mathrm{Ar})_{n}$ clusters when $\mathrm{n}$ increases.

Molecular clusters $\left(\mathrm{H}_{2} \mathrm{O}, \mathrm{NH}_{3}\right.$ and DME) with mercury are rather different. In the excited state the $\mathrm{Hg}^{*}-$ Molecule interaction cannot be considered as a van der Waals ${ }^{16}$ type interaction but is nearly a chemical bond. In the excited state this notion of additivity of pair potentials will not be valid.

From the experiments the most important points to be discussed are the following:

- there is no fundamental evolution in the spectroscopy of $\mathrm{Hg}(\mathrm{Mol})_{\mathrm{n}}$ when the size of the cluster is increasing whereas for $\mathrm{HgAr}_{\mathrm{n}}$ the spectroscopy changes drastically from $\mathrm{HgAr}$ to $\mathrm{HgAr}_{4}$.

- for $\mathrm{Hg}_{2}(\mathrm{Mol})_{\mathrm{n}}$ the state correlating the $\mathrm{Hg}_{2}\left(\mathrm{O}_{\mathrm{u}}^{+}\right)$does absorb in the neighborhood of the $\mathrm{Hg}_{2}$ absorption. The lower state correlating to $\mathrm{Hg}_{2}\left(1_{u}\right)$ shows a very wide absorption in the $\mathrm{Hg}_{2}$ absorption range with a red shifted onset which depends on the solvent.

- the $\mathrm{Hg}-\mathrm{Hg}$ dissociation in the ionic $\mathrm{Hg}_{2}(\mathrm{Mol})_{\mathrm{n}}^{+}$clusters has been observed when $\mathrm{Hg}_{2}(1 \mathrm{u})(\mathrm{Mol})_{\mathrm{n}}$ is vibrationally excited and disappears at lower energy. 
- The dissociation of $\mathrm{Hg}_{2}(\mathrm{Mol})_{\mathrm{n}}$ into $\mathrm{Hg}_{2}+(\mathrm{Mol})_{\mathrm{n}}^{+}$has been observed for $\mathrm{H}_{2} \mathrm{O}$ and $\mathrm{NH}_{3}$ but not for DME.

\section{a) Excitation spectra of $\mathrm{Hg}(\mathrm{Mol})$}

Persistence of two excited states in the $\mathrm{Hg}(\mathrm{Mol})_{\mathrm{n}}$ clusters can be simply explained in the following manner:

- In the excited state the mercury atom is linked by a strong bond to one molecule of the molecular cluster as in the excited 1-1 complex.

- In the excited state when other molecules are added to the $\mathrm{Hg}^{*}-\mathrm{Mol}$ complex one can consider that the binding energy for this added molecule is nearly the same as in the ground state. In other words in the excited state there is one quasi chemical bond, the other molecules being spectators.

This model of an $\mathrm{Hg}^{*}-\mathrm{Mol}$ preferential bond may explain the similarity of the spectra for the small clusters despite the fact that the geometries in the ground state of these clusters are quite different. In fact if the disappearance of the red shifted state in the case of $\mathrm{Hg}(\mathrm{Ar})_{n}$ cluster was a sign of beginning of solvation of the metal by the rare gas atoms, for water and ammonia there is no solvation of mercury (the metal stays at the surface of the cluster) but for DME it seems that the mercury disturbs relatively strongly the solvent cluster. If in the excited state, there is one strong $\mathrm{Hg}-\mathrm{Mol}$ bond and all the other $\mathrm{Hg}-\mathrm{Mol}$ interactions are nearly equivalent to the ones in the ground state, then the spectra of these small clusters will be quite insensitive to solvation effects as observed.

Some ground state structural effects may be observed by comparing the $\mathrm{Hg}\left(\mathrm{NH}_{3}\right)_{\mathrm{n}}$ and $\mathrm{Hg}\left(\mathrm{H}_{2} \mathrm{O}\right)_{n}$ spectra. In water clusters the contours of both X-A and X-B transitions are more clearly defined than in ammonia clusters. Molecular Dynamics calculations have shown that in the ground state some isomers with similar binding energies can co-exist in $\mathrm{Hg}\left(\mathrm{NH}_{3}\right)_{\mathrm{n}}$ whereas mainly one isomer is found for $\mathrm{Hg}\left(\mathrm{H}_{2} \mathrm{O}\right)_{\mathrm{n}}$. This can lead to an overlap of the spectra of the $\mathrm{Hg}\left(\mathrm{NH}_{3}\right)_{\mathrm{n}}$ isomers and broadening of the absorption band in $\mathrm{Hg}\left(\mathrm{NH}_{3}\right)_{\mathrm{n}}$ as compared to $\mathrm{Hg}\left(\mathrm{H}_{2} \mathrm{O}\right)_{\mathrm{n}}$.

The strong change observed for $\mathrm{Hg}\left(\mathrm{H}_{2} \mathrm{O}\right)_{n \geq 8}$ with the narrowing of the absorption band is not understood but does not seem to be due to a solvation process. A possible explanation is the crossing of the excited state correlating with $\mathrm{Hg}\left({ }^{3} \mathrm{P}_{1}\right)$ with another one which is not clearly identified. One possible mechanism would be a crossing with the ionic $\mathrm{Hg}^{+} \times\left(\mathrm{H}_{2} \mathrm{O}\right)_{\mathrm{n}}^{-}$potential. For smaller clusters for which the electron affinity of water clusters is $\operatorname{low}^{42}(<0.2 \mathrm{eV}$ for $\mathrm{n} \leq 7)$ this potential lies probably above the neutral potential curve and the interaction is small. For larger cluster the electron affinity of water clusters increases, the charge transfer curve will be lower and the interaction between the two states also increases. This explanation is coherent with the fact that this narrowing is not observed for the $\mathrm{Hg}\left(\mathrm{NH}_{3}\right)_{\mathrm{n}}$ clusters the electron affinities of ammonia clusters being much lower than the water ones and nearly constant up to $\mathrm{n}=35.42,43$ 
b) Excitation spectra of $\mathrm{Hg}_{2}(\mathrm{Mol})_{n}$

In the excitation process one can consider that in a simple approach two chromophores within the cluster can be excited: the $\mathrm{Hg}-\mathrm{Hg}$ dimer solvated by molecules or the $\mathrm{Hg}$-molecule complex surrounded by one $\mathrm{Hg}$ atom and the other molecules. For both $\mathrm{Hg}_{2}\left(1_{u}\right)$ and $\mathrm{O}_{u}^{+}$states the excitation spectra are similar to the spectra of $\mathrm{Hg}_{2}$. The absorption of the second chromophore $(\mathrm{Hg}$-molecule surrounded by one $\mathrm{Hg}$ atom and the other molecules) would be similar to the absorption of the $\mathrm{Hg}-(\mathrm{Mol})_{\mathrm{n}}$ system. In this case the remaining $\mathrm{Hg}$ atom in its ground state will be very weakly bond to the cluster (as in the ground state) and since the excitation process leads to a high vibrational excess energy of the cluster, this $\mathrm{Hg}$ atom may evaporate quickly. These excited clusters will appear at the $\mathrm{Hg}(\mathrm{Mol})_{\mathrm{n}}^{+}$mass and will not be distinguished from the direct excitation of the $\mathrm{Hg}(\mathrm{Mol})_{\mathrm{n}}$ clusters.

The assumption above seems to be justified by the excitation spectra of $\mathrm{Hg}_{2}(\mathrm{Mol})_{\mathrm{n}}$ (water, ammonia and DME) which are weakly dependent on the nature of the ligands and on the number of molecules and which all present a relatively narrow absorption band $\left( \pm 400 \mathrm{~cm}^{-1}\right)$ in the $\mathrm{Hg}_{2} \mathrm{O}_{\mathrm{u}}^{+}$energy range. It should be noticed that if one can excite the $\mathrm{Hg}_{2} \mathrm{O}_{\mathrm{u}}^{+}$chromophore within the cluster the energy does not stay localized. Indeed the measurement of the ionization threshold potential from this state is found higher than the one found when the $\mathrm{Hg}_{2}\left(1_{u}\right)(\mathrm{Mol})_{\mathrm{n}}$ is the intermediate state. This is interpreted as non radiative relaxation of $\mathrm{Hg}_{2} \mathrm{O}_{\mathrm{u}}^{+}(\mathrm{Mol})_{\mathrm{n}}$ towards $\mathrm{Hg}_{2}\left(1_{\mathrm{u}}\right)(\mathrm{Mol})_{\mathrm{n}-\mathrm{x}}$, some energy being lost in this process through IVR and evaporation. For symmetry reasons such a process does not occur in free $\mathrm{Hg}_{2}$, and the ionization threshold found when the $\mathrm{O}_{\mathrm{u}}^{+}$intermediate state is excited is lower than for the $1_{\mathrm{u}}$ state $(8.8 \mathrm{eV}$ and $9.0 \mathrm{eV}$ respectively).

Whereas the excitation of the $\mathrm{Hg}_{2}\left(1_{u}\right)$ transition leads to maximum of the absorption band which is not shifted as compared to $\mathrm{Hg}_{2}$, the onset of the spectrum is red shifted $\left(-4,300 \mathrm{~cm}^{-1}\right.$ for water, $-7,700 \mathrm{~cm}^{-1}$ for DME to be compared with $-2,000$ $\mathrm{cm}^{-1}$ for the bands on the $\mathrm{Hg}_{2}$ spectrum). This means that the presence of a solvent molecule affects $\mathrm{Hg}_{2}{ }^{*}$ and the Franck-Condon factors from the ground state to the lower vibrational states are different than in the bare $\mathrm{Hg}_{2}$ species. This can be due to the following effects: the temperature of the $\mathrm{Hg}_{2}(\mathrm{Mol})_{\mathrm{n}}$ might be higher than the temperature of the $\mathrm{Hg}_{2}$ observed without the presence of the molecules in the jet due to the release of the heat formation of the clusters during the expansion. Since the $\mathrm{Hg}_{2}$ ground state vibrational frequency is only $19 \mathrm{~cm}^{-1},{ }^{17}$ a small increase of the temperature might populate some excited vibrational levels which have better Franck-Condon factor towards the lower vibrational level of the $\mathrm{Hg}_{2}\left(1_{\mathrm{u}}\right)$ state. Moreover the laser used in the $300 \mathrm{~nm}$ spectral region $\left(-6,000 \mathrm{~cm}^{-1}\right)$ are more powerful than in the $260 \mathrm{~nm}\left(-1,000 \mathrm{~cm}^{-1}\right)$ region. Weakly allowed Franck-Condon transitions are enhanced in this region.

This crude model of the two transitions does not explain the variation of the red shift onset with the molecular solvent. However it should be noticed that the observed onset follows the strength of the $\mathrm{Hg}-\mathrm{Mol}$ binding energy in the A state: $\mathrm{H}_{2} \mathrm{O}<\mathrm{NH}_{3}$ $<$ DME. 
However this model of two chromophores can be used to understand the dissociation process observed for these clusters.

\section{c) Dissociation process in $\mathrm{Hg}_{2}\left(\mathrm{I}_{u}\right)(\mathrm{Mol})_{n}$}

The dissociation channel of $\mathrm{Hg}_{2}(\mathrm{Mol})_{\mathrm{n}}^{+}$ionized via the state correlating with $\mathrm{Hg}\left(1_{\mathrm{u}}\right)$ in one color experiments leads to $\mathrm{Hg}(\mathrm{Mol})_{x}^{+}+\mathrm{Hg}(\mathrm{Mol})_{y}$. This dissociation occurs in a slightly different energy domain from the absorption of the $\mathrm{Hg}_{2}\left(1_{\mathrm{u}}\right)(\mathrm{Mol})_{\mathrm{n}}$ clusters (see results), the onset of dissociation being situated at $-3,700 \mathrm{~cm}^{-1}$ for $\mathrm{Hg}_{2}\left(\mathrm{H}_{2} \mathrm{O}\right)_{\mathrm{n}}$, $-5,500 \mathrm{~cm}^{-1}$ for $\mathrm{Hg}_{2}\left(\mathrm{NH}_{3}\right)_{\mathrm{n}}$ and $-6,600 \mathrm{~cm}^{-1}$ for $\mathrm{Hg}_{2}(\mathrm{DME})_{\mathrm{n}}$.

The existence of an onset in the fragments spectra may be explained by the following mechanism. One may assume that this threshold is due to the competition between an excitation of the $\mathrm{Hg}-\mathrm{Mol}$ or the $\mathrm{Hg}-\mathrm{Hg}$ bond in the cluster. At low photon energy only the $\mathrm{Hg}-\mathrm{Hg}$ transition can be excited and will lead to the $\mathrm{Hg}_{2}^{+}$evaporation (except for DME) since the excitation of the $\mathrm{Hg}-\mathrm{Hg}$ bond leads to the formation of a strongly bound $\mathrm{Hg}$ dimer bond by weak forces to the molecular cluster. The direct excitation of the $\mathrm{Hg}-\mathrm{Mol}$ transition or its excitation through an IVR process will lead after absorption of two other photons to the rupture of the $\mathrm{Hg}-\mathrm{Hg}$ bond in the ion since in the excitation of the $\mathrm{Hg}-\mathrm{Mol}$ bond, the second mercury atom becomes left bond: only by van der Waals forces. This mechanism will be energetically possible if the photon energy in the first step is high enough to reach the bottom of the $\mathrm{Hg}^{*}-\mathrm{Mol}$ bond. This can be calculated using the data given in scheme 1 .

$$
\left.\mathrm{E}_{\text {min }}=\mathrm{E}\left(\mathrm{Hg}{ }^{3} \mathrm{P}_{1} \leftarrow{ }^{1} \mathrm{~S}_{0}\right)-\mathrm{E}_{\text {bind. }}(\mathrm{Hg}-\mathrm{Mol}) *+\mathrm{E}_{\text {bind }} \text { ( } \mathrm{Hg}-\mathrm{Mol}\right)
$$

The values for $\mathrm{E}_{\text {bind }}\left(\mathrm{Hg}\left(\mathrm{H}_{2} \mathrm{O}\right)\right)^{*}=3,000 \mathrm{~cm}^{-1},\left(\mathrm{Hg}\left(\mathrm{NH}_{3}\right)\right)^{*}=6,000 \mathrm{~cm}^{-1}$ and $(\mathrm{Hg}(\mathrm{DME}))^{*}=7,200 \mathrm{~cm}^{-1}$ lead to thresholds wavelengths in agreement with the experiment: $-2,600 \mathrm{~cm}^{-1}$ for water (exp: $-3,700 \mathrm{~cm}^{-1}$ ), $5,700 \mathrm{~cm}^{-1}$ for ammonia (exp: $-5,500 \mathrm{~cm}^{-1}$ ) and $-6,700 \mathrm{~cm}^{-1}$ for DME (exp: $-6,600 \mathrm{~cm}^{-1}$ ).

\section{d) Properties common to the three solvents}

Although for the three types of ligands the structures of the smallest $\mathrm{Hg}_{1,2}(\mathrm{Mol})_{\mathrm{n}}$ clusters in the ground state are different, many experimental behaviors are similar (absorption region, dissociation channel. .). This seems to be due to the formation in the excitation process of one quasi chemical bond in the clusters even in the smallest clusters. This bond is only slightly perturbed by the other molecules when the cluster size is increasing. Formation of quasi chemical bonds in the clusters makes difficult a theoretical evaluation of spectral shifts in the excitation spectra: modelization by purely additive potentials in the excited states is not reasonable.

\section{e) Most important differences: role of the geometry}

The most important differences for the ground state geometries between the three ligands are observed for the larger clusters. For water and ammonia, due to the 
hydrogen bonds, the Mol-Mol bond is strong as compared to the $\mathrm{Hg}-\mathrm{Mol}$. The cluster structure consists in a molecular cluster with mercury sitting on its surface.

For DME the binding energies of Mol-Mol and $\mathrm{Hg}-\mathrm{Mol}$ are nearly the same. The DME cluster is perturbed by the mercury atom in order to increase the number of $\mathrm{Hg}-\mathrm{Mol}$ interactions, the metal atom or dimer can be considered as nested inside the molecular cluster.

Only one experimental result may reflect the differences in geometry of the clusters.

- The dissociation process $\mathrm{Hg}_{2}\left(\mathrm{H}_{2} \mathrm{O}\right)_{\mathrm{n}}^{+}$and $\mathrm{Hg}_{2}\left(\mathrm{NH}_{3}\right)_{\mathrm{n}}^{+}$leading to the dissociation in $\mathrm{Hg}^{+}(\mathrm{Mol})_{\mathrm{n}}$ with a charge transfer to the water cluster or the ammonia cluster followed by a rearrangement in $\mathrm{H}^{+}\left(\mathrm{H}_{2} \mathrm{O}\right)_{n}$, or $\mathrm{H}^{+}\left(\mathrm{NH}_{3}\right)$ (these rearrangements are well known in the pure ionized water or ammonia clusters ${ }^{44-47}$ ) is not observed for DME although the ionization potential of DME $(\mathrm{IP}=9.96 \mathrm{eV})$ is nearly equal to the one of $\mathrm{NH}_{3}(10.2 \mathrm{eV})$ and much lower than that of water $(12.6 \mathrm{eV})$.

For $\mathrm{Hg}_{2}$ water or ammonia small clusters where the dimer lies at the surface, these two dissociation processes are observed but for DME where the mercury dimer is better surrounded by the ligands which increases number of $\mathrm{Hg}-\mathrm{Mol}$ interactions, this may unfavor the metal/(ligand) ${ }_{\mathrm{n}}$ rupture.

\section{CONCLUSION}

The spectra of $\mathrm{Hg}_{1,2}(\mathrm{Mol})_{\mathrm{n}}$ clusters in the vicinity of the $\mathrm{Hg}\left({ }^{3} \mathrm{P}_{1} \leftarrow{ }^{1} \mathrm{~S}_{\mathrm{O}}\right)$ transition are not strongly dependent on the cluster size and upon the cluster ground state geometry, in contrast to $\mathrm{Hg}-\mathrm{Ar}_{\mathrm{n}}$. This behavior is due to the strong "quasi chemical bond" between the excited $\mathrm{Hg}$ atom and one molecule of the molecular cluster, the other solvent molecules being spectator. In $\mathrm{HgAr}_{\mathrm{n}}$ there is no such chemical bond, thus all the argon atoms are equivalent and contribute to the excited state binding energy, and therefore the spectrum is very sensitive to the cluster size and geometry.

The only effect which can be assigned to the ground state geometry of the clusters is seen in the dissociation channels of the $\mathrm{Hg}_{2}(\mathrm{Mol})_{\mathrm{n}}^{+}$.

\section{Acknowledgment}

The authors are indebted to $\mathrm{C}$. Crépin, A. Tramer for providing us with preprints prior to publications and for helpful discussions and to O. Benoist d'Azy for her help in data analysis.

\section{References}

1. M. Ito. J. Mol. Structure, 177, 173 (1988)

2. M. Ito, T. Ebata, N. Mikami. Ann. Rev. Phys. Chem., 39, 123 (1988) and references therein

3. M. B. Knickelbein and W. J. C. Menezes. Chem. Phys. Lett., $184(5,6), 433$ (1991)

4. M. B. Knickelbein and W. J. C. Menezes. J. Chem. Phys., 94 (6), 4111 (1991)

5. E. K. Parks, T. D. Klots and S. J. Riley. J. Chem. Phys., 92 (6), 3813 (1990) 
6. F. Misaizu, K. Tsukamoto, M. Sanekata and K. Fuke. Chem. Phys. Lett., $188(3,4) 241$ (1992)

7. C. P. Schulz, R. Haugstätter, H-U. Tittes and I. V. Hertel. Z. Phys. D-Atoms, Molecules and Clusters., 10, 279 (1988)

8. C. Nitsh, C. P. Schulz, A. Gerber, W. Zimmermann-Edling and I. V. Hertel. Z. Phys. D- Atoms, Molecules and Clusters, 22, 651 (1992)

9. I. V. Hertel, C. Hüglin, C. Nitsch and C. P. Schulz. Phys. Rev. Lett., 67 (13), 1767 (1991)

10. S. Leutwyler and J. Bösiger. Chem. Rev., 90, 489 (1990) and references therein

11. J. Jortner. Z. Phys. D, Atoms, Molecules and Clusters, 24, 247 (1992) and references therein

12. C. Lardeux-Dedonder, C. Jouvet, M. Richard Viard and D. Solgadi. Chem Phys Lett., 170, 153 (1990)

13. C. Lardeux-Dedonder, C. Jouvet, M. Martrenchard-Barra, D. Solgadi, A. Tramer. Z. Phys. D- Atoms, Molecules and Clusters, 20, 73 (1991)

14. M. C. Duval, B. Soep, R. D. van Zee, W. B. Bosma et T. S. Zwier. J. Chem. Phys., 88 (4), 2148 (1988)

15. M. C. Duval and B. Soep. J. Phys. Chem., 95 (23), 9075 (1991)

16. W. H. Breckenridge, M. C. Duval and B. Soep. J. Phys. Chem., 95, 7153 (1991)

17. A. Zehnacker, M. C. Duval, C. Jouvet, C. Lardeux-Dedonder, D. Solgadi, B. Soep and O. Benoist d'Azy. J. Chem. Phys., 86 (11), 6565 (1987)

18. R. D. van Zee, S. C. Blankespoor and T. S. Zwier. J. Chem. Phys., 88 (8), 4650 (1988)

19. K. Balasubramanian, K. K. Das and D. W. Liao. Chem. Phys. Lett., 195, 487 (1992) and references therein

20. C. Dedonder-Lardeux, C. Jouvet, S. Martrenchard and D. Solgadi. J. Chem. Phys., 98 (7) 5281 (1993)

21. M. Chergui, C. Crépin, T. Hebert and A. Tramer. Chem. Phys. Lett., 197, 467 (1992)

22. C. Crépin and A. Tramer. J. Chem. Phys., 97, 4472 (1992)

23. S. Martrenchard-Barra. thèse Université de Paris Orsay 1993

24. C. Jouvet, A. Beswick. J. Chem. Phys., 86, 5500 (1987)

25. F. G. Amar. Proceedings of the Int. School of Physics "Enrico Fermi", Course VII, The Chemical Physics of Atomic and Molecular Clusters, G. Scoles Ed., North Holland (1990)

26. L. Perera and F. Amar. J. Chem. Phys., 934884 (1990)

27. W. H. Breckenridge, C. Jouvet and B. Soep. J. Chem. Phys., 84, 1443 (1986)

28. M. C. Duval and B. Soep. Chem. Phys. Lett., 141, 225 (1987)

29. J. R Reimers and R. O. Watts. Chem. Phys., 85, 83 (1984)

30. D. F. Coker and R. O. Watts. J. Phys. Chem., 91, 2513 (1987)

31. J. R. Reiners, R. O. Watts, J. Chem. Phys. 85, 83 (1984)

32. J. C. Greer, R. Ahlrichs and I. V. Hertel. Chem. Phys., 133, 191 (1989)

33. K. P. Sagarik, R.Ahlrichs and S. Brode. Mol. Phys., 57 (6), 1247 (1986)

34. D. D. Nelson Jr, G. T. Fraser and W. Klemperer. J. Chem. Phys., 83 (12), 6201 (1985)

35. S. Y. Liu, C. E. Dykstra, K. Kolenbrander and J. M. Lisy. J. Chem. Phys., 85 (4), 2077 (1986)

36. D. D. Nelson Jr., W. Klemperer, G. T. Fraser, F. J. Lovas and R. D. Sueram. J. Chem. Phys., 87 (11), 6364 (1987)

37. D. M. Hassett, C. J. Marsden and B. J. Smith. Chem. Phys. Lett., 183 (5), 449 (1991)

38. B. Heijmen, A. Bizzari, S. Stolte and J. Reuss. Chem. Phys., 126, 201 (1988)

39. W. Kamke, R. Hermann, Z. Wang and I. V. Hertel. Z. Physik D.-Atoms, Molecules and Clusters, 491 (1988)

40. F. A. Momany, L. M. Carruthers, R. F. McGuire and H. A. Scheraga. J. Phys. Chem., 78 (16), 1595 (1974)

41. G. Nemethy, M. S. Pottle and H. A. Scheraga. J. Phys. Chem., 87, 1883 (1983)

42. G. H. Lee, S. T. Arnold, J. G. Eaton, H. W. Sarkas, K. H. Bowen, C. Ludewigt and H. Haberland. Z. Phys. D-Atoms, Molecules and Clusters, 20, 9 (1991)

43. R. N. Barnett, U. Landmann, C. L. Cleveland, N. R. Kestner and J. Jortner. Chem. Phys. Lett., 148 $(2,3), 249(1988)$

44. a/ S. T. Ceyer, P. W. Tiedemann, B. H. Michan and Y. T. Lee. J. Chem. Phys., 70, 14 (1979)

45. K. Stephan, J. H. Futrel, K. I. Peterson, A. W. Castelman Jr, H. E. Wagner, N. Djuric and T. D. Märk. Intern. J. Mass Spectrom. Ion Phys., 44, 167 (1982)

46. O. Echt, P. P. Dao, S. Morgan and A. W. Castelman Jr. J. Chem. Phys., 82, 4076 (1985)

47. C. Y. Ng, D. J. Trevor, P. W. Tiedemann, S. T. Ceyer, P. L. Kronebusch, B. H. Mahan and Y. T. Lee. J. Chem. Phys., 67 (9), 4235 (1977) 